\title{
Chiari I malformation, syringomyelia and papilledema: a malformative complex connected to oculo-auriculo-vertebral spectrum
}

\author{
Agostino Berio, ${ }^{1}$ Giacomo Garlaschi, ${ }^{2}$ Giuseppe Mangiante, ${ }^{1}$ Gian Luigi Mariottini, ${ }^{3}$ Attilia Piazzi ${ }^{1}$ \\ ${ }^{1}$ Department of Neurosciences, Rehabilitation, Ophthamology, Genetics and Mother-Child Sciences; ${ }^{2}$ Department of \\ Health Sciences; ${ }^{3}$ Department of Earth, Environment and Life Sciences, University of Genoa, Italy
}

\begin{abstract}
The authors discuss the association of papilledema with Chiari I malformation (CMI) and syringomyelia on the basis of a clinical case studied by radiology, immunology and biochemistry methods. In the presence of normal haematology, blood immunology and biochemistry, clinical signs of headache and papilledema associated to hemifacial asymmetry, blind neck fistulas, malformed ears and spinal abnormalities (symptoms of oculo-auricolo-vertebral spectrum - OAVS), were observed. Magnetic resonance images and computed tomography demonstrated the occurrence of lowered cerebellar tonsils, but with values lower than those typical of the CMI syndrome and syringomyelia. The
\end{abstract}

Correspondence: Agostino Berio, Department of Neurosciences, Rehabilitation, Ophthamology, Genetics and Mother-Child Sciences, University of Genoa, via G. Gaslini 5, 16145 Genoa, Italy.

E-mail: Agostinoberio@ospedale-gaslini.ge.it

Gian Luigi Mariottini, Department of Earth, Environment and Life

Sciences, University of Genoa, Italy.

E-mail: Gian.Luigi.Mariottini@unige.it

Key words: Chiari I malformation; Papilledema; Syringomyelia; Headache; Facial abnormalities; Neural crest cells; Oculo-auriculo-vertebral spectrum extension; Lumbo-peritoneal shunt.

Contributions: the authors contributed equally.

Conflict of interest: the authors declare no potential conflict of interest.

Funding: none.

Conference presentation: this work was partially presented at the National Congress of the Italian Pediatrics Society, Bologna May 8-10, 2013.

Received for publication: 14 December 2018.

Revision received: 3 February 2019.

Accepted for publication: 20 February 2019.

(C) Copyright A. Berio et al., 2019

Licensee PAGEPress, Italy

Journal of Biological Research 2019; 92:8001

doi:10.4081/jbr.2019.8001

This article is distributed under the terms of the Creative Commons Attribution Noncommercial License (by-nc 4.0) which permits any noncommercial use, distribution, and reproduction in any medium, provided the original author(s) and source are credited. authors concluded for a minor form (benign ectopia) in the CMI syndrome, associated to papilledema and syringomyelia, and hypothesize an unique pathogenetic mechanism for this complex, connected to neural crest cell development and to OAVS, as extension of this spectrum. The authors underline the relevance of the facial/neck lateral signs for the diagnosis of OAVS associated to brain stem pathology and CMI.

\section{Introduction}

The association of papilledema with Chiari I malformation (CMI) and syringomyelia has been rarely reported and the pathogenesis of this complex is not completely understood: it is thought to be a complex malformation connected to oculo-auriculo-vertebral spectrum (OAVS), a neural crest cells (NCC)-derived disease.

Michaud and Sheridan ${ }^{1}$ reported the association of Goldenhar syndrome (at present considered a particular form of OAVS) with CMI and syringomyelia; subsequently, Inci and Sağlam ${ }^{2}$ reported about this association in another patient. Papilledema was also reported in $\mathrm{CMI}^{3}$ and discussed in Goldenhar syndrome by Kirkham. ${ }^{4}$

Here we report and discuss the association of CMI with syringomyelia and papilledema, and the possible relationships with OAVS.

\section{Materials and Methods}

Haematological, biochemical, endocrinological and immunological tests were carried out by common laboratory methods.

Motor Evoked Potentials were evaluated after transcranial magnetic stimulation and recorded from the opponens pollicis during $30 \%$ of maximal contraction, according to standard methods. Somato Sensory Evoked Potentials (SSEPs) were recorded after stimulation of median nerve at wrist. Active electrodes placed over the sixth cervical vertebra were utilized to evaluate spinal responses, placing reference electrodes over thyroid cartilage; the same placement (reference electrodes over thyroid cartilage) was utilized to record peripheral nerve potentials from Erb's point. SSEPs were recorded after stimulation of tibialis nerve at ankle by standard techniques. Cortical responses were recorded from the parietal scalp.

Magnetic Resonance Images (MRI) were acquired by standard methods.

The evaluation was carried out on a female patient who was followed from infancy to date. 


\section{Results}

None of relatives of the patient suffered from neurological or ophthalmological problems. The patient complained from infancy of headache episodes, some with aura and other without aura, with normal EEG. From 24 years of age, she suffered from myopia (right eye -1.75; left eye -3.25), which was corrected with spherical lenses, and from retro-orbital and sub-occipital pain, exacerbated by Valsalva manoeuvre. Eye consultation showed normal papilla, retinal and visual fields, tone and ocular motility.

At 26 years of age, she suffered from daily episodes of vertex headache associated to ocular phenomena (amaurosis preceded by sparking scotomata at the right eye, interesting subsequently the left eye) and to desultory paresthesias at the right hemisoma, dysarthria and confusion. These symptoms were treated with analgesics and tryptans with slight results.

At 30 years of age, the patient showed facial asymmetry (left hemiface<right), bilateral microtia, and abnormal ear lobule with Darwin tubercle; she showed blind skin fistulas (branchial clefs residual) at left side of neck (Figure 1). Neurological examination showed decreased osteo-tendineous (OT) reflexes on the left upper extremity, but hyperactive ones on the lower limb. Cranial nerves and gait were normal. Ophthalmological examination showed bilateral papilledema and ocular fields bilaterally restricted, mainly on the left side.

MRI showed relatively lowered cerebellar tonsils, asymmetry (left $<$ right) of cerebral lateral ventricles, tiny hyperintensity of perivascular gliosis in subcortical white matter of both hemispheres and pons, and venous dysplasia with little angioma in white matter below the right ventricular horn. Angio-MRI demonstrated thin left sinus transversus, jugular sinus and jugular vein, as well as asymmetry of the lateral venous sinuses (left $<$ right) with abnormal insertion of the superior longitudinal sinus on the lateral right sinus. Carotid Doppler was normal. Lumbar puncture showed high pressure $\left(220 \mathrm{~mm} \mathrm{H} \mathrm{H}_{2} \mathrm{O}\right)$ of Cerebro Spinal Fluid (CSF); haematological, serological, biochemical and cytological values were normal (Table 1).

Pseudotumor cerebri associated to venous Central Nervous System abnormalities, headache, analgesics and tryptans intoxication were diagnosed.

At 30 years and 8 months of age, after subtraction of $11 \mathrm{ml}$ of CSF, acetazolamide was started and continued for three months with improvement of headache. At 31 years, hormonal and immunological tests were normal (Tables 2 and 3). Neoplasia and autoimmune diseases were excluded according to Fornaro et al. ${ }^{5,6}$

Neuro-ophthalmological consultation showed mild sectorial papilledema at left eye, normal right fundus, and reduced visual fields (left $>$ right). On this basis, a possible opticopathy was suspected. At 31 years and 8 months of age, a second CSF evaluation demonstrated raised pressure $\left(250 \mathrm{~mm} \mathrm{H}_{2} \mathrm{O}\right) ; 7 \mathrm{~mL}$ of CSF were subtracted, resulting in final pressure of $160 \mathrm{~mm} \mathrm{H}_{2} \mathrm{O}$.

Furosemide therapy was started and continued in following days. Visual Evocated Potentials showed signs of abnormality of stimulus conduction evidenced by reduced amplitude and raised latency on left side (a condition induced by optical nerve pathology). Headache persisted, mainly at the right side. Romberg sign was present. At 32 years of age, before surgery, haematological, biochemical, hormonal (Tables 1-3), and cardiological (Table 4) tests were normal; a subarachnoideal-spinal/peritoneal shunt (lumbo-peritoneal shunt) was done in order to lower CSF pressure.

The patient felt well, without headache during six months; haematological, biochemical, and hormonal tests were normal (Tables 1 and 2). Thereafter, an episode of tachycardia, raised arte- rial pressure, short breath, left arm pain with subsequent numbness of the left arm, was reported. ECG and cardiology were normal. Thyroid hormones and cathecolamines were in normal range (Table 2). Radiology showed some flexions of the catheter; Computed Tomography (CT) demonstrated low position of cerebellar tonsils. The episode spontaneously resolved.

At 34 years, cerebral MRI demonstrated normal ventricular volume; cerebellar tonsils were relatively lowered having tip at level of foramen magnum (Figure 2). Myelo-MRI showed expansion of spinal chord from D8 to D10 with a cystic intramedullary dorsal structure, including the central canal and containing a fluid similar to CSF (Figure 3). Syringomyelia with hydromyelia were diagnosed. Anti-aquaporin 4 antibodies were negative (Table 3). Rachis MRI showed reduced normal lumbar lordosis, with disc protrusion at D9D10, and at L2-L3; disc bulging at L3-L4 and L4-L5. Routine tests were normal. Visual fields, ocular pressure and papilla were unaltered. Headache ameliorated. At 34 years 6 months the previous MRI at the foramen magnum level was confirmed (Figure 4).

At 35 years 11 months, the patient presented neck pain irradiated to face and left hemisoma after neck flexion, followed by vomit, dysarthria, and falling. This episode lasted 30 minutes and was followed by numbness. The symptoms resolved after placing the patient in horizontal position for 48 hours; the patient sensed shunt discharge in peritoneum and slight abdominal pain. Lactacidemia was $20 \mathrm{mg} / \mathrm{dL}$ (normal values $10-19 \mathrm{mg} / \mathrm{dL}$ ). Neurophysiological tests demonstrated normal central motor conduction velocity time (assessed by cortical stimulation) on right side; on the left side tibialis anterior laevus raised latency was present (31.1 $\mathrm{ms}$ by cortical stimulation; $13.5 \mathrm{~ms}$ by radicular stimulation; TCCM $=17.6$ ), as expression of cortico-spinal dysfunction. SSEPs by median nerve stimulation on wrist resulted in normal cervical responses, central conduction time, cervical responses latency, and

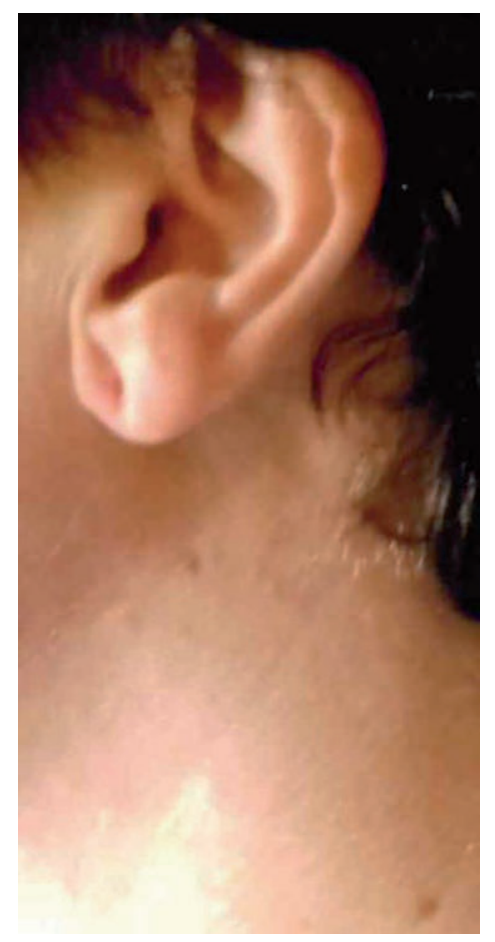

Figure 1. Occurrence of microtia, abnormal ear lobule, Darwin tubercle, blind skin fistulas at left neck in the patient. 
cortical response latency, bilaterally. After tibial nerve stimulation on ankle the cortical response of reference peak P40 showed bilateral SSEPs latency delay (44.8 ms on right and $46.8 \mathrm{~ms}$ on left). Morphology and amplitude of potentials were normal. These results were compatible with syringomyelia (Table 5). At 36 years of age a new episode of pain was signalled; CT showed further descent of cerebellar tonsils.

\section{Discussion and Conclusions}

In summary, at MRI the patient presented low cerebellar tonsils, not more than $5 \mathrm{~mm}$ below of the occipital foramen, associat- ed to episodes of vertex and sub-occipital pain, headache, raised by Valsalva manoeuvre, pseudotumor cerebri with raised CSF pressure and scotomata, retro-orbital pain in the presence of normal haematological, biochemical, immunological and hormonal tests, as already reported by Milhorat et al. ${ }^{3}$

The placement of a lumbo-peritoneal shunt caused partial disappearance of symptoms, according to Sullivan et al., ${ }^{7}$ but subsequently they re-appeared associated to tachycardia, raised arterial pressure, concomitant to a geniculation of the lumbo-peritoneal catheter. Similar symptoms were reported in another occasion, after head flexion, as already reported by Tubbs et al. ${ }^{8}$ Recently, descent of cerebellar tonsils more than previously observed was demonstrated by CT. After shunting, syringomyelia was showed. A diagnosis of CMI syndrome was considered, based on clinical symptoms.

Table 1. Hematological and blood biochemistry values at different age of the patient.

\begin{tabular}{|c|c|c|c|c|}
\hline \multirow[t]{2}{*}{ Hematology } & \multicolumn{3}{|c|}{ Age } & \multirow[b]{2}{*}{ Normal values } \\
\hline & 30 y $4 \mathrm{~m}$ & $\begin{array}{c}32 \mathrm{y} \\
\text { (before surgery) }\end{array}$ & $\begin{array}{l}32 \text { y } 4 \mathrm{~m} \\
\text { (after surgery) }\end{array}$ & \\
\hline White cells $/ \mathrm{mm}^{3}$ & 9650 & 7360 & n.d. & $4000-10000$ \\
\hline Red cells/mm $/ m^{3}$ & 5090000 & 5080000 & n.d. & $4000000-5500000$ \\
\hline Haemoglobin (g/dL) & 14.9 & 14.7 & n.d. & $12-16$ \\
\hline Platelets $/ \mathrm{mm}^{3}$ & 312000 & 257000 & n.d. & $150000-400000$ \\
\hline Neutrophils (\%) & 69.9 & 69.1 & n.d. & $55-70$ \\
\hline Lymphocytes (\%) & 23.7 & 25.0 & n.d. & $25-48$ \\
\hline Monocytes (\%) & 3.3 & 5.0 & n.d. & $1-13$ \\
\hline Basophils (\%) & 0.4 & 0.1 & n.d. & $0-1.5$ \\
\hline Eosinophils (\%) & 1.3 & 0.8 & n.d. & $1-5$ \\
\hline \multicolumn{5}{|l|}{ Blood biochemistry } \\
\hline Azotaemia (mg/dL) & 20.0 & 20.0 & n.d. & $10-50$ \\
\hline Glycaemia (mg/dL) & 104.0 & 94.0 & 97.0 & $70-110$ \\
\hline Creatinine (mg/dL) & 0.77 & 0.6 & 0.6 & $0.5-1.1$ \\
\hline $\mathrm{Na}(\mathrm{mEq} / \mathrm{L})$ & 138 & 135 & 136 & $135-145$ \\
\hline $\mathrm{K}(\mathrm{mEq} / \mathrm{L})$ & 4.2 & 4.2 & 4.0 & $3.5-4.5$ \\
\hline $\mathrm{Cl}(\mathrm{mEq} / \mathrm{L})$ & 103 & n.d. & n.d. & $96-105$ \\
\hline $\mathrm{pH}$ & 7.38 & n.d. & n.d. & $7.35-7.45$ \\
\hline Venous $\mathrm{pCO}_{2}(\mathrm{mmHg})$ & 30.5 & n.d. & n.d. & $30-35$ \\
\hline Excess Bases $(\mathrm{mmol} / \mathrm{L})$ & -5.7 & n.d. & n.d. & \pm 2 \\
\hline Bicarbonate standard (mEq/L) & 16.0 & n.d. & n.d. & $22-29$ \\
\hline Glutamic Oxalacetic Transaminase (UI/L) & 19 & 28 & 14 & $0-31$ \\
\hline Glutamic Pyruvic Transaminase (UI/L) & 20 & 33 & 17 & $0-30$ \\
\hline$\gamma$-Gamma Glutamyl Transferase (UI/L) & 20 & 13 & 20 & $5-36$ \\
\hline Alkaline phosphatase (UI/L) & 79 & 75 & 63 & $35-105$ \\
\hline Pseudocholinesterase (UI/L) & 10407 & 9361 & 5320 & $5320-12920$ \\
\hline Creatin Phospho Kinase (UI/L) & 82 & 63 & 63 & $10-140$ \\
\hline C Reactive Protein (CRP) (mg/dL) & 4 & 0.17 (n.v. <0.5) & n.d. & $0-5$ \\
\hline Total cholesterol (mg/dL) & 184 & 199 & 190 & $130-200$ \\
\hline High Density Lipoprotein cholesterol (mg/dL) & n.d. & 57 & 63 & $65-80$ \\
\hline Low Density Lipoprotein cholesterol (mg/dL) & n.d. & 123 & 102 & $<140$ \\
\hline Tryglycerides (mg/dL) & 112 & 97 & 114 & $30-200$ \\
\hline Proteins $(\mathrm{g} / \mathrm{dL})$ & 7.2 & 7.2 & n.d. & $6-8$ \\
\hline Lactic Dehydogenase (UI/L) & n.d. & 202 & n.d. & $135-214$ \\
\hline Red cells sedimentation rate (mm/hour) & 30 & 15 & 4 & $0-20$ \\
\hline
\end{tabular}


CMI is characterized by cerebellar tonsil descent at least 5 $\mathrm{mm}$ below the foramen magnum, ${ }^{3}$ as demonstrated by T1weighted MRI, but some patients at surgery presented lower tonsillar descent, even though accompanied by clinical symptoms of CMI. ${ }^{8}$

At present, CMI is considered to be due to a disproportion between the underdeveloped posterior cranial fossa and the brain stem, with compression of the hindbrain, consequent descent of cerebellar tonsils ${ }^{3,9}$ and CSF flow disturbances. Brain stem compression and fluid disturbances are responsible of headache, neck pain, pseudotumor-like symptoms and of the possible hydrocephalus, syringomyelia and compression of other nervous tissues. ${ }^{3}$

Not all patients with CMI exhibit tonsillar herniation of $5 \mathrm{~mm}$ or more: out of 364 patients reported by Milhorat et al. ${ }^{3}$ with this syndrome, 32 exhibited tonsillar descent less than $5 \mathrm{~mm}$ (benign tonsillar ectopia $)^{8}$, but they were diagnosed as having CMI due to typical symptoms.

Oakes ${ }^{10}$ and Tubbs et al. ${ }^{8}$ reported that $50-75 \%$ of patients with CMI showed syringomyelia. On the basis of these reports, the diagnosis of CMI may be possible in the absence of $5 \mathrm{~mm}$ tonsillar descent, if syringomyelia is present and associated to clinical symptoms of CMI. ${ }^{3,8}$ In these patients, decreased velocity flow in the cisterna magna, cisterna pre-pontina, pre-medullary spaces and in subarachnoid spaces were reported. ${ }^{3}$

The CMI anomaly may be sporadic, autosomal dominant or recessive trait ${ }^{3,11}$ in some families, or may be associated to osteochondrodystrophies. ${ }^{12}$

The frequent association between CMI and syringomyelia induced to consider CMI as a leading cause of syringomyelia., 3

Ball and Dayan ${ }^{13}$ stated that in communicating syringomyelia

Table 2. Hormones and their metabolites in blood and urine of the patient.

\begin{tabular}{|c|c|c|c|c|c|}
\hline Blood Hormones & 30 y 4 m & $\begin{array}{l}31 \mathrm{y} \\
\text { (before surgery) }\end{array}$ & $\begin{array}{c}\text { Age } \\
32 \mathrm{y} 4 \mathrm{~m} \\
\text { (after surgery) }\end{array}$ & $\begin{array}{l}32 \text { y } 6 \mathrm{~m} \\
\text { (after pain episode) }\end{array}$ & Normal values \\
\hline FT3 (pg/mL) & 3.3 & 2.85 & n.d. & n.d. & $1.8-4.2$ \\
\hline FT4 (pg/mL) & 13.8 & 12.6 & n.d. & 10.9 & $8.0-19.0$ \\
\hline Thyroid-Stimulating Hormone (TSH) $(\mu \mathrm{U} / \mathrm{mL})$ & 2.12 & 0.88 & n.d. & 1.62 & $0.5-4.4$ \\
\hline Prolactine $(\mathrm{ng} / \mathrm{mL})$ & 32.41 & 17.0 & n.d. & n.d. & $3-20$ \\
\hline Parathormone (PTH) (pg/mL) & n.d. & 49.0 & n.d. & n.d. & $18-87$ \\
\hline Antithyroglobulin Ab (chemiluminescence) & $<20$ & n.d. & n.d. & n.d. & $<40$ \\
\hline Blood cortisol ( $\mu \mathrm{g} / \mathrm{dL})$ & n.d. & n.d. & 15.3 & n.d. & $5-25$ \\
\hline Dehydroepiandrosterone sulfate (DHEAS) $(\mu \mathrm{g} / \mathrm{dL})$ & L) n.d. & n.d. & 159 & n.d. & $35-430$ \\
\hline Adrenocorticotropic Hormone (ACTH) (pg/mL) & n.d. & n.d. & 12.1 & n.d. & $9-52$ \\
\hline Aldosterone (ng/dL) & n.d. & n.d. & 11.2 & n.d. & $2.4-22.0$ \\
\hline Renine $(\mu \mathrm{U} / \mathrm{mL})$ & n.d. & n.d. & 9.1 & n.d. & $4.4-46.0$ \\
\hline \multicolumn{6}{|l|}{ Urine hormone metabolites } \\
\hline Vanilmandelic acid (mg/24 hours) & n.d. & n.d. & n.d. & 5.9 & $<7.5$ \\
\hline Homovanilic acid (mg/24 hours) & n.d. & n.d. & n.d. & 6.6 & $<7.5$ \\
\hline Epinephrine ( $\mu \mathrm{g} / 24$ hours) & n.d. & n.d. & n.d. & 10.6 & $<14.9$ \\
\hline Nor-Epinephrine ( $\mu \mathrm{g} / 24$ hours) & n.d. & n.d. & n.d. & 38.5 & $<66.07$ \\
\hline Dopamine ( $\mu \mathrm{g} / 24$ hours) & n.d. & n.d. & n.d. & 366 & $<591.80$ \\
\hline
\end{tabular}

Table 3. Immunological situation of the patient.

\begin{tabular}{lcc} 
Blood immunology & At 31 years of age, before surgery & Normal values \\
Anti-endomysium Ab (immunofluorescence) & Negative & Negative \\
Anti-transglutaminase Ab (UR/ml) & $<2$ & $<20$ \\
\hline Anti Nuclear Antibody (ANA) & Negative & Negative $(\leq 1: 40)$ \\
Extractable Nuclear Antigen (ENA) screen & Negative & Negative \\
\hline Islet Cell Antibodies (ICA) & Negative & Negative $(\leq 1: 10)$ \\
Glutamic Acid Decarboxylase (GAD) antibody & 5 Ul/mL & Positive $\geq 10$ \\
\hline Anti-DNA Ab & Negative & Negative $(\leq 1: 10)$ \\
\hline Circulating immunocomplexes & & Positive $>4$ \\
Anti Clq antibody & $2 \mu \mathrm{gEq} / \mathrm{mL}$ (negative) \\
C3 complement component & $8 \mu \mathrm{gEq} / \mathrm{mL}$ (negative) & Positive $>20$ \\
\hline Aquaporin 4 (NMO IgG) Ab & Negative & Negative
\end{tabular}




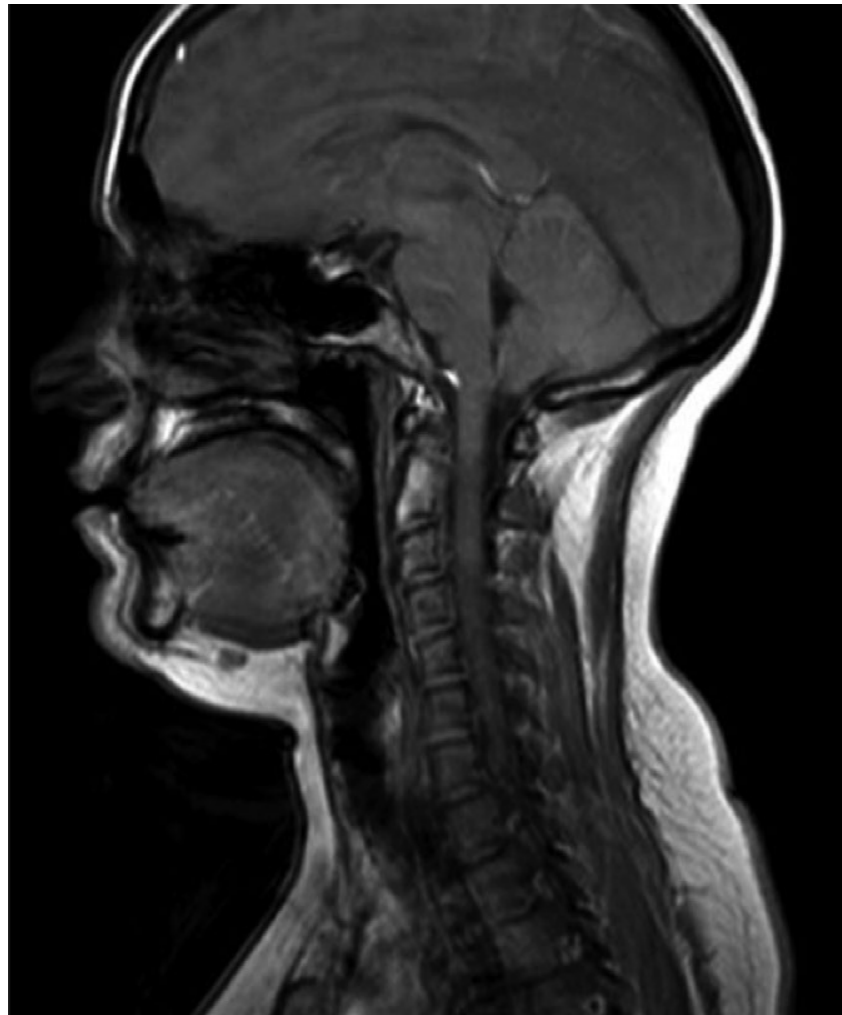

Figure 2. Sagittal MRI of the posterior fossa and upper cervical spine at 34 years, after shunting. Tonsil tips lowered no more than $5 \mathrm{~mm}$ from the plane of foramen magnum.

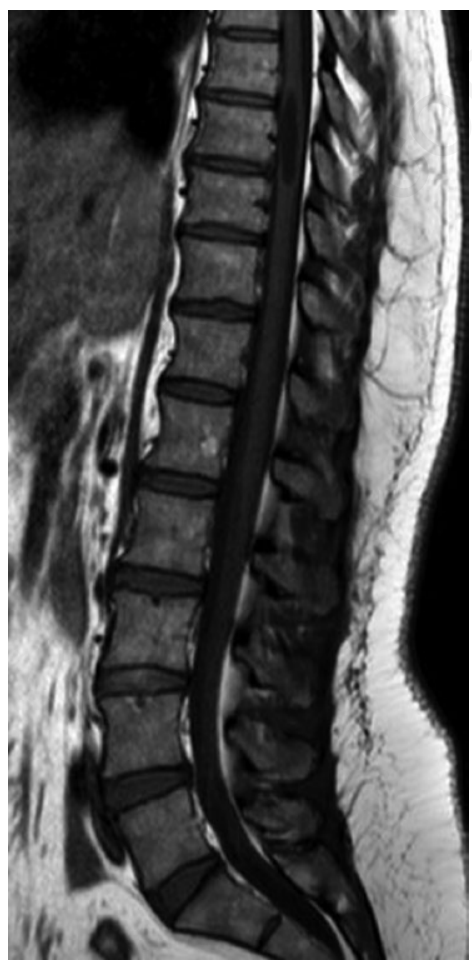

Figure 3. Sagittal MRI of dorso-lumbar spine. Presence of a cavity filled with a cerebro-spinal like liquid. a foramen magnum abnormality is always present and this condition could act as valvular obstruction to the upward flow of the CSF during coughing, straining, posture changing and muscular activity. ${ }^{14}$ If the hindbrain lesion acting as valve does not permit the prevention of the normal dissipation of waves associated to these physiological activities and transmitted from the subarachnoideal spinal space, the pressure waves might inverted and spread CSF in the chord along the perivascular Virchow-Robin spaces, causing syrinx. This mechanism is also reported in the patient subgroup, who do not exhibit frank tonsillar ectopia, but a benign tonsillar ectopia ${ }^{8}$ with associated syrinx. This condition is considered as CMI because it presents positive results on syringomyelia after the posterior fossa decompression. ${ }^{8}$

On the basis of the pre-surgical symptomatology (mainly papilledema and headache), this condition could have been present in our patient before shunting.

In some cases, syrinx of CMI may be an acquired condition, consequent to spinal peritoneal shunt placement, with increased spinal CSF absorption due to the high intracerebral-spinal pressure gradient which could induce the tonsillar descent and, due to Ball and Dayan ${ }^{13}$ mechanism, the syrinx formation. ${ }^{7,15}$

Scoliosis may be associated to syringomyelia; in $4 \%$ of symptomless patients who undergo surgery for scoliosis, syringomyelia

Table 4. Cardiological results in the patient before surgery.

\begin{tabular}{lc} 
Parameter & Recorded value \\
Arterial Pressure (AP) (Riva Rocci) & $90 / 60 \mathrm{mmHg}$ \\
Heart beat frequency & $54 / \mathrm{min}$ \\
\hline Respiration frequency (breaths) & $12 / \mathrm{min}$ \\
Body temperature & $36.6^{\circ} \mathrm{C}$ \\
\hline ECG & normal \\
\hline
\end{tabular}

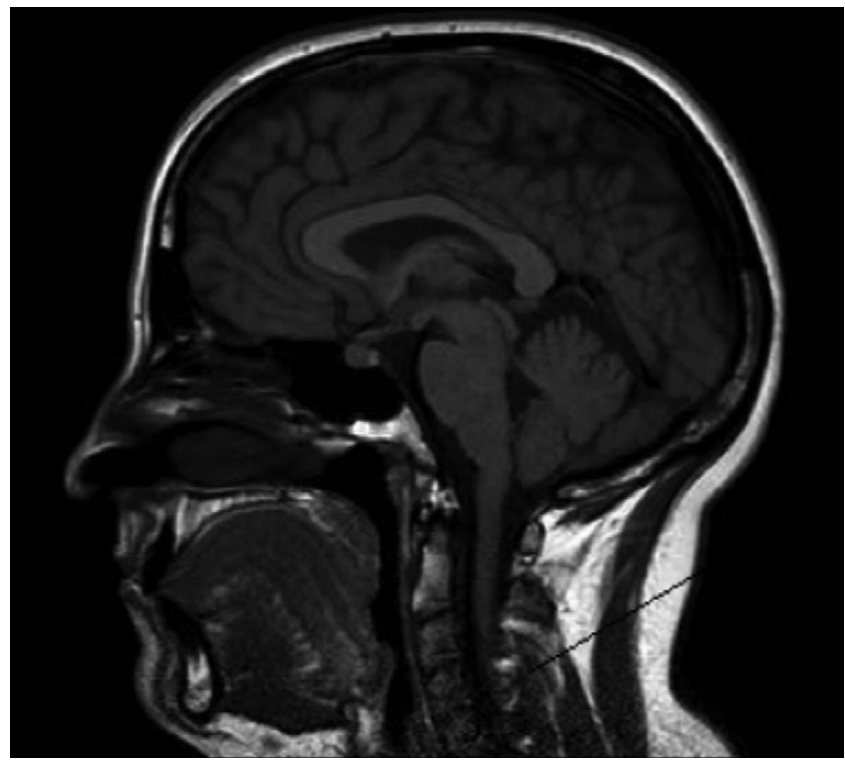

Figure 4. Sagittal cranial MRI at 34 years 6 months, confirming previous tonsil tips position. 
Table 5. A: Motor Evoked Potentials following transcranial magnetic stimulation showing raised latency in left inferior limb due to delay of motor central conduction to left inferior limbs. B: Somato-sensorial evoked potentials following median nerve stimulation at wrist: values within normal range. C: Somato-Sensorial Evoked Potentials after stimulation of tibialis nervus at ankle; cortical response: bilateral delay of latency of reference peak P40 (left $>$ right).

\begin{tabular}{|c|c|c|c|}
\hline $\begin{array}{l}\text { A } \\
\text { Musculus }\end{array}$ & Cortical stimulation(msec.) & Radicular stimulation(msec.) & TCCM \\
\hline Opponens pollicis dexter & 19 (n.v. $19.5 \pm 1.5$ ) & 12.4 & 6.60 \\
\hline Opponens pollicis laevus & 18.5 (n.v. $18.5 \pm 1.5)$ & 12.4 & 6.10 \\
\hline Tibialis anterior dexter & 28.5 (n.v. $29 \pm 1.5)$ & 12.9 & 15.6 \\
\hline Tibialis anterior laevus & 31.1 (n.v. $28.5 \pm 1.5$ ) & 13.5 & 17.6 \\
\hline \multicolumn{4}{|l|}{ B } \\
\hline Cervical response & & Right & Left \\
\hline Latency of the reference peak N13 & msec (n.v. <16.3) & 13.7 & 13 \\
\hline Cortical response latency of the reference peak N20 & msec. (n.v. <22.1) & 20.2 & 19.5 \\
\hline Central conduction time & msec. (n.v. <6.8) & 6.50 & 6.50 \\
\hline \multicolumn{4}{|l|}{ C } \\
\hline Cortical response latency of the reference peak P40 & msec. (n.v. <40) & 44.8 & 46.8 \\
\hline
\end{tabular}

was present ${ }^{16,17}$ as expression of a common malformative pathogenetic mechanism. ${ }^{18}$ In some cases scoliosis is associated to syringomyelia and to CMI. ${ }^{1,2}$

In our patient, spinal abnormalities (reduced lordosis, protrusion of lumbar disks) may have a relationship with CMI abnormality and syringomyelia.

Tubbs et al. ${ }^{8}$ reported a particular condition, connected to CMI malformation and observed in $8 \%$ of cases of this syndrome: the occurrence of thin arachnoid membrane occluding the Magendie foramen, not demonstrated at MRI, but diagnosed at surgery. This condition caused CSF flow defect and CMI malformation and was resolved after bone cerebellar fossa decompression and membrane ablation $^{8}$. In our patient this condition may be excluded, owing to the positive functionality of shunt, ${ }^{7}$ but it poses the issue of the association of facial abnormalities with cerebellar and posterior cranial fossa malformations. ${ }^{19,20}$

Couly and Aicardi ${ }^{19}$ reported the frequent association of lateral facial abnormalities, maxillo-mandibular disostoses present in Goldenhar/OAVS syndrome, with malformations of brain stem, cerebellum, meninges, posterior cranial fossa, and attributed these abnormalities to NCC abnormal migration-proliferation and integration with the mesoderm. ${ }^{20,21}$

In our patient, mild hemifacial microsomia, ear abnormalities, ${ }^{22}$ skin blind fistulas, homolateral to prevalent papilledema, to lateral venous sinus cerebral hypoplasia, and to underdeveloped cerebral left ventricle are present on left side and are associated to brain stem, ocular and spinal abnormalities. All these malformations are mild, but the symptomatology is clinically relevant. These malformations depose for a complex malformation syndrome reminiscent of OAVS, ${ }^{23-28}$ associated to CMI malformation, syringomyelia and papilledema. This association, here reported first to our knowledge, should be a typical neurocristopathy due to abnormal proliferation, migration or integration of $\mathrm{NCC}$ with tissues ${ }^{21}$ and to their regulatory role on the mesoderm development. ${ }^{19,21-23,25-28}$ On this basis, in our case, CMI abnormality may be congenital, associated to papilledema and syringomyelia with spinal abnormalities, and connected to OAVS as extension of this spectrum. This case underlines the relevance of the development of studies connected to clinical signs, ${ }^{29}$ although mild, for taking the diagnosis, and the need of early surgical therapy in the presence of papilledema to avoid the blindness. After five years from surgery, the patient is well, without papilledema and with only a mild restriction of visual fields. Further studies are necessary to confirm this unitary pathogenetic hypotheses of CMI syndrome, syringomyelia, papilledema, and OAVS.

\section{References}

1. Michaud C, Sheridan S. Goldenhar's syndrome associated with cranial and neurological malformations. Can J Ophthalmol 1974;9:347-50.

2. Inci S, Sağlam S. Syringohydromyelia as a complication of Goldenhar syndrome. Childs Nerv Syst 1995;11:708-11.

3. Milhorat TH, Chou MW, Trinidad EM, et al. Chiari I malformation redefined: clinical and radiographic findings for 364 symptomatic patients. Neurosurgery 1999;44:1005-17.

4. Kirkham TH. Cervico-oculo-acusticus syndrome with pseudopapilloedema. Arch Dis Child 1969;44:504-8.

5. Fornaro R, Frascio M, Stabilini C, et al. Crohn's disease surgery: problems of postoperative recurrence. Chir Ital 2008;60:761-81.

6. Fornaro R, Frascio M, Denegri A, et al. Malattia di Crohn e cancro. Ann Ital Chir 2009;80:119-26.

7. Sullivan LP, Stears JC, Ringel SP. Resolution of syringomyelia and Chiari I malformation by ventriculoatrial shunting in a patient with pseudotumor cerebri and a lumboperitoneal shunt. Neurosurgery 1988;22:744-7.

8. Tubbs RS, McGirt MJ, Oakes WJ. Surgical experience in 130 pediatric patients with Chiari I malformations. J Neurosurg 2003;99:291-6.

9. Fujita K, Matsuo N, Mori O, et al. The association of hypopituitarism with small pituitary, invisible pituitary stalk, type 1 Arnold-Chiari malformation, and syringomyelia in seven patients born in breech position: a further proof of birth injury theory on the pathogenesis of "idiopathic hypopituitarism". Eur J Pediatr 1992;151:266-70. 
10. Oakes WJ. Chiari Malformations, Hydromyelia, and Syringomyelia. In: Wilkins R, Rengachary S, eds. Neurosurgery, ed 2nd. New York: McGraw-Hill; 1996. pp 3593-3616.

11. McLone DG, Knepper PA. The cause of Chiari II malformation: a unified theory. Pediatr Neurosci 1989;15:1-12.

12. Gripp KW, Scott CI Jr, Nicholson L, et al. Chiari malformation and tonsillar ectopia in twin brothers and father with autosomal dominant spondylo-epiphyseal dysplasia tarda. Skeletal Radiol 1997;26:131-3.

13. Ball MJ, Dayan AD. Pathogenesis of syringomyelia. Lancet 1972;2:799-801.

14. Hirata Y, Matsukado Y, Kaku M. Syringomyelia associated with a foramen magnum meningioma. Surg Neurol 1985;23:291-4.

15. Welch K, Shillito J, Strand R, et al. Chiari I "malformations"an acquired disorder? J Neurosurg 1981;55:604-9.

16. Arai S, Ohtsuka Y, Moriya H, et al. Scoliosis associated with syringomyelia. Spine 1993;18:1591-2.

17. Williams B. On the pathogenesis of syringomyelia: a review. J R Soc Med 1980;73:798-806.

18. Eule JM, Erickson MA, O’Brien MF, Handler M. Chiari I malformation associated with syringomyelia and scoliosis: a twenty-year review of surgical and nonsurgical treatment in a pediatric population. Spine (Phila Pa 1976) 2002;27:1451-5.

19. Couly G, Aicardi J. Associated morphological anomalies of the face and brain in infants [in French]. Arch Fr Pediatr 1988;45: 99-104.

20. Couly G. Nouvelle conception de la maladie et du syndrome de Pierre Robin: dysneurulation du rombencephale. Rev Stomat Chir Maxi Fac 1983;84:225-32.
21. Le Douarin N. The neural crest. Cambridge: Cambridge University Press; 1982.

22. Berio A, Piazzi A. Cisti aracnoidea, ipoplasia del lobo temporale destro ed anomalie facciali: una neurocristopatia. Min Pediatr 2009;61:441-4.

23. Luquetti DV1, Heike CL, Hing AV, Cunningham ML, Cox TC. Microtia: epidemiology and genetics. Am J Med Genet A 2012;158A:124-39.

24. Mellor DH, Richardson JE, Douglas DM. Goldenhar's syndrome. Oculoauriculo-vertebral dysplasia. Arch Dis Child 1973;48:537-41.

25. Berio A, Mangiante G, Oliaro E, Piazzi A. Oculo-auriculo-vertebral spectrum (OAVS) with large cerebral cyst: affinity to holoprosencephaly. Min Pediatr 2012;64:549-55.

26. Berio A, Garlaschi G, Piazzi A. Precocious puberty in a patient with Oculo-Auriculo-Verebral spectrum (OAVS). Pediatr Med Chir 2014;36:135-40.

27. Tasse C, Böhringer S, Fischer S, et al. Oculo-auriculo-vertebral spectrum (OAVS): clinical evaluation and severity scoring of 53 patients and proposal for a new classification. Eur J Med Genet 2005;48:397-411.

28. Tasse C, Majewski F, Böhringer S, et al. A family with autosomal dominant oculo-auriculo-vertebral spectrum. Clin Dysmorphol 2007;16:1-7.

29. Stabilini C, Bracale U, Pignata G, et al. Laparoscopic bridging vs. anatomic open reconstruction for midline abdominal hernia mesh repair [LABOR]: single-blinded, multicenter, randomized, controlled trial on long-term functional results. Trials 2013;14:357-60. 